\title{
Definitive radiotherapy for squamous cell carcinoma of the oral cavity: a single- institution experience
}

\author{
Kristin Lang1,2,3, Melissa Baur ${ }^{1}$, Thomas Held ${ }^{1,2,3}$, Rami El Shafie ${ }^{1,2,3}$, Julius Moratin ${ }^{4}$, \\ Christian Freudlsperger ${ }^{4}$, Karim Zaoui ${ }^{5}$, Nina Bougatf ${ }^{1,2,6}$, Jürgen Hoffmann ${ }^{4}$, \\ Peter K. Plinkert ${ }^{5}$, Jürgen Debus , $^{1,2,3,6,7}$, Sebastian Adeberg ${ }^{1,2,3,6}$ \\ 1 Department of Radiation Oncology, Heidelberg University Hospital, Heidelberg, Germany \\ ${ }^{2}$ Heidelberg Institute of Radiation Oncology (HIRO), Heidelberg University Hospital, Heidelberg, Germany \\ ${ }^{3}$ National Center for Tumor diseases (NCT), Heidelberg University Hospital, Heidelberg, Germany \\ ${ }^{4}$ Department of Oral and Maxillofacial Surgery, Heidelberg University Hospital, Heidelberg, Germany \\ ${ }^{5}$ Department of Otorhinolaryngology, Head and Neck Surgery, Heidelberg University Hospital, Heidelberg, Germany \\ ${ }^{6}$ Heidelberg Ion beam Therapy Center (HIT), Department of Radiation Oncology, Heidelberg University Hospital, \\ Heidelberg, Germany \\ ${ }^{7}$ Clinical Cooperation Unit Radiation Oncology, German Cancer Research Center (DKFZ), Heidelberg, Germany
}

Radiol Oncol 2021; 55(4): 467-473

Received 13 May 2021

Accepted 21 September 2021

Correspondence to: Kristin Lang, M.D., Department of Radiation Oncology, Heidelberg University Hospital, Im Neuenheimer Feld 400, D-69120 Heidelberg, Germany. E-mail: Kristin.lang@med.uni-heidelberg.de

Disclosure: No potential conflicts of interest were disclosed.

This is an open access article under the CC BY-NC-ND license (http://creativecommons.org/licenses/by-nc-nd/4.0/).

Background. Surgery is standard of care for oral cavity cancer $(\mathrm{OCC})$. We provide a single-institution experience using definitive radiotherapy (RT) with or without concurrent systemic therapy for primary unresectable OCC.

Patients and methods. We retrospectively examined 49 patients with non-metastatic primary unresectable OCC treated with definitive RT between 2000 and 2019. The majority of patients (63.3\%) were treated with definitive chemoradiotherapy while $26.5 \%$ were given single-agent cetuximab weekly simultaneous to definitive RT. Five patients were treated with definitive RT alone because of limited disease and no nodal involvement.

Results. Median follow-up was 73 months (range, 6-236 months), median progression free survival (PFS) was 42 months (range, 2-157 months), median local disease-free survival (LDFS) was 44 months (range, 2-157 months) and median overall survival (OS) from the time of RT initiation was 52 months (range, 5-236 months). There were 65.3\% locoregional failures, $84.4 \%$ local and $15.6 \%$ distant metastasis. The majority of patients with local failure presented with American Joint Committee on Cancer (AJCC) Stage III-IV disease (59.2\%). The 5-year Kaplan-Meier estimates for OS (III-IV vs. I-II) was $22.8 \%$ vs. $54.2 \%$ ( $p=0.03$, HR 2.090, 1.1-4.2). Patients who were treated with systemic therapy had a significant better 5 -year overall survival compared to those with RT alone $(43.9 \% \mathrm{vs} .23 .1 \%, p=0.05,1.0-4.1)$. RT with doses less than 70 Gy $(p=0.046$, HR $2.1 \quad(1.0-4.5)$ was associated with worse overall survival. Mucositis was the most common $\geq$ grade 3 acute toxicity and occurred in 19 patients (39\%). Incidences of chronic toxicities were loss of taste, trismus, osteoradionecrosis and xerostomia.

Conclusions. Definitive RT with or without concurrent systemic agents in patients with unresectable OCC resulted in an eloquent rate of locoregional control and good overall survival rates and is currently the best available treatment option in this patient collective.

Key words: oral cancer; systemic therapy; definitive radiotherapy; local failure 


\section{Introduction}

Oral cancer includes cancers of all subsites of the oral cavity (oral tongue, floor of mouth, buccal mucosa, upper lip, lower lip, upper gum, lower gum, palate, and retromolar area) and is the eighth most common cancer worldwide. ${ }^{1,2}$ Worldwide incidence of oral cancer in 2018 was four cases per 100,000 people. ${ }^{3}$ Most related risk factors for oral cancer belong to tobacco and alcohol use. ${ }^{4}$

Treatment of oral cavity cancer (OCC) includes single modality surgery, radiotherapy (RT) or various combinations of these modalities with or without systemic agents. The selection of treatment is based on disease stage, considerations of disease control, anticipated functional and cosmetic outcomes and expertise. Standard treatment option for OCC is surgery. ${ }^{5}$ Primary RT with or without systemic therapy is not used routinely. There are less prospective trials available which directly compared primary surgery $v s$. primary RT in oral squamous cell carcinoma (OSCC) specifically. ${ }^{5-8}$ In literature 5-year overall survival rate since first diagnosis in patients treated with RT alone was $15 \%{ }^{6,9}$ To improve local control and overall survival rates intensified treatment with concurrent chemotherapy to RT is necessary instead of RT alone. ${ }^{9,10}$ Stenson et al. reported in a retrospective series overall survival rates with $66.9 \%$ in locally advanced oral cancer patients (stage III-IV) undergoing concurrent chemoradiotherapy (CCRT). ${ }^{10}$ In a meta-analysis from Pignon et al. of individual patient data from clinical trials comparing RT vs. CCRT (MACH-NC) in locally advanced head and neck cancers, OCC comprised $21 \%$ of cases. Results showed an improvement of survival in OCC with CCRT compared to RT alone. ${ }^{9-11}$

To examine the clinical significance and outcome in patients who do not underwent surgery we retrospectively reviewed our experience in treating OCC with primary RT with or without concurrent systemic therapies.

\section{Patients and methods}

This study was performed following institutional guidelines and the Declaration of Helsinki of 1975 in its most recent version. Ethical approval for the study was given from the local ethics committee at University Hospital Heidelberg (S421-2015).

Clinical, operative, and hospital course records were reviewed. We analyzed data from Nationales Centrum für Tumorerkrankungen (NCT) Cancer
Registry in Heidelberg and imported data into our HIRO Research Database. ${ }^{12}$ All patients underwent systemic workup including cross-sectional imaging with referring providers prior to commencing RT. Afterwards, the patients underwent CT simulation with a standard immobilization 5-point mask. Target volume definition was based on CT and MRI scans with contrast agents, included the primary tumor region as well as nodal involvement according to the International Commission on Radiation Units and Measurements (ICRU) definition. ${ }^{11-16}$ Patients underwent regular follow-up, including CT examinations every three months in the first two years after definitive treatment, in year three and four every 6 months and year five and six once a year as well as regularly clinical examinations at the Department of Oral and Maxillofacial Surgery. All follow-up CT-scans were reviewed by an experienced radiologist by the institutions own diagnostics. We excluded all patients with a metastatic disease (M1) at initial diagnosis.

\section{Treatment toxicity}

Acute toxicity was evaluated during and at the end of RT. Late toxicity was evaluated minimum 90 days after completion of RT and was described according to the Common Terminology Criteria for Adverse Events (CTCAE) criteria (version 4.03, U.S. Department of Health and Human Services, Washington, DC, USA).

\section{Statistical analysis and outcome evaluation}

Overall survival (OS), progression free survival (PFS) and local disease-free survival (LDFS) were calculated using Kaplan-Meier analysis. OS was calculated from the time of RT initiation until death or the date of last follow-up. PFS was calculated as the time from RT initiation to tumor progression or death/ date of last follow-up, whichever occurred first. LRFS was defined as the time from RT initiation until local tumor progression at the primary tumor site. Patients still alive at the time of analysis, without tumor progression, or patients lost to follow-up were censored. Kaplan-Meier estimates were calculated using IBM SPSS software version 24. Subgroups were compared using the log-rank test. p-values of 0.05 or less were considered statistically significant. For comparison between groups, the Chi-squared test was performed in categorical and continuous variables. Kaplan-Meier estimates of potential prognostic factors were compared us- 
ing the log-rank test for univariate analysis and the cox-regression model for multivariate analysis.

\section{Results}

\section{Patient characteristics}

There were 49 patients treated either with definitive RT alone or in combination with chemotherapy/immunotherapy at the Department of Radiation Oncology, University Hospital of Heidelberg. Only patients with cancer of the oral tongue (23 patients), floor of mouth (21 patients) and buccal mucosa (4 patients) were included (ICD-O-3 topography codes $\mathrm{C} 02-\mathrm{C} 06$ ).

Information regarding a risk factor history was available for all patients, there were 19 patients current and former smokers, 10 patients with alcohol consumption and 61 patients had a smoking and drinking history. Detailed patient characteristics are shown in Table 1.

\section{Treatment characteristics}

RT was carried out using photon irradiation with either 3D-planned (17 patients, 34.7\%), IMRT (32 patients, $65.3 \%$ ) (TomoTherapy ${ }^{\circledR}$, Accuray, Sunnyvale, CA, USA) or volume-modulated RT (VMAT) (Elekta, Sweden), with treatment delivered one fraction per day with 5 fractions per week. The main RT treatment features are listed in Table 2.

There were 5 patients $(10.2 \%)$ treated with RT alone because of limited disease or no nodal involvement. The majority of patients (31 patients, $63.3 \%)$ were treated with single-agent cisplatin $40 \mathrm{mg} / \mathrm{m}^{2}$ chemotherapy weekly and 13 patients $(26.5 \%)$ were given single-agent cetuximab $400 \mathrm{mg} /$ $\mathrm{m}^{2}$ one week prior to start of treatment followed by $250 \mathrm{mg} / \mathrm{m}^{2}$ weekly as an alternative to chemotherapy.

\section{Treatment results for the whole cohort}

After a median follow-up of 73 months (range, 6-236 months), 11 patients (22.4\%) were still alive, while 38 patients (77.6\%) had died: 31 (81.6\%) due to disease progression and $7(18.4 \%)$ due to pulmonary infection, cardiac disease, secondary carcinoma or other comorbidities. There were 32 patients (65.3\%) with locoregional failures in this cohort, 27 patients (84.4\%) of which were local failures alone and 5 patients $(15.6 \%)$ were distant. The majority of patients who failed locally presented with American Joint
TABLE 1. Patient characteristics

\begin{tabular}{ll}
\hline Characteristic & Number of patients (percentage) \\
\hline Gender & $30(61.2 \%)$ \\
\hline Male & $19(38.8 \%)$ \\
Female & \\
\hline Age, years & 61 years (17-85 years) \\
\hline Median (range) & \\
\hline T-stage & $8(16.3 \%)$ \\
\hline T1 & $12(24.5 \%)$ \\
T2 & $7(14.3 \%)$ \\
T3 & $22(44.9 \%)$ \\
T4 & \\
\hline N-stage & $20(40.8 \%)$ \\
N0 & $29(59.2 \%)$ \\
N+ & \\
\hline Grading & $5(10.2 \%)$ \\
\hline 1 & $10(20.4 \%)$ \\
2 & $34(69.4 \%)$ \\
\hline Risk factors & $29(59.2 \%)$ \\
\hline Smoking history & $6(12.2 \%)$ \\
Alcohol consumption & $14(28.6 \%)$ \\
\hline
\end{tabular}

TABLE 2. RT treatment characteristics

\begin{tabular}{|c|c|}
\hline \multicolumn{2}{|l|}{ Technique } \\
\hline 3D-CRT & $17(34.7 \%)$ \\
\hline IMRT & $32(65.3 \%)$ \\
\hline \multicolumn{2}{|l|}{ RT-Dose } \\
\hline $\begin{array}{l}\text { Median total dose base plan } \\
\text { (without boost) }\end{array}$ & 57.5 Gy (range: 50.0-65.9 Gy) \\
\hline $\begin{array}{l}\text { Median single dose base plan } \\
\text { (without boost) }\end{array}$ & 1.9 Gy (range: 1.7-2.1 Gy) \\
\hline \multicolumn{2}{|l|}{ Boost } \\
\hline Yes & $45(91.8 \%)$ \\
\hline SIB & $38(84.4 \%)$ \\
\hline Sequential & $7(15.6 \%)$ \\
\hline no & $4(8.2 \%)$ \\
\hline Median total dose boost plan & 12.0 Gy (range: 8.0-20.0 Gy) \\
\hline Median single dose boost plan & 2.2 Gy (range: $2.0-2.2 \mathrm{~Gy}$ ) \\
\hline $\begin{array}{l}\text { Cumulative total dose } \\
\text { (base + boost plan) }\end{array}$ & 70.0 Gy (range: 60.0-72.0 Gy) \\
\hline \multicolumn{2}{|l|}{ RT-Volume } \\
\hline CTV dimension base plan & $\begin{array}{l}829.6 \mathrm{ccm} \text { (range: } 61.7-1554.4 \\
\mathrm{ccm} \text { ) }\end{array}$ \\
\hline CTV dimension boost plan & $178.5 \mathrm{ccm}$ (range: $31.4-535.8 \mathrm{ccm}$ ) \\
\hline
\end{tabular}

$\mathrm{CTV}=$ clinical target volume; $\mathrm{Gy}=$ gray; IMRT = intensity modulated radiotherapy, $\mathrm{RT}=$ radiotherapy $\mathrm{SIB}=$ simultaneous integrated boost; $3 \mathrm{D}-\mathrm{CRT}=$ three dimensional-conformal radiotherapy 


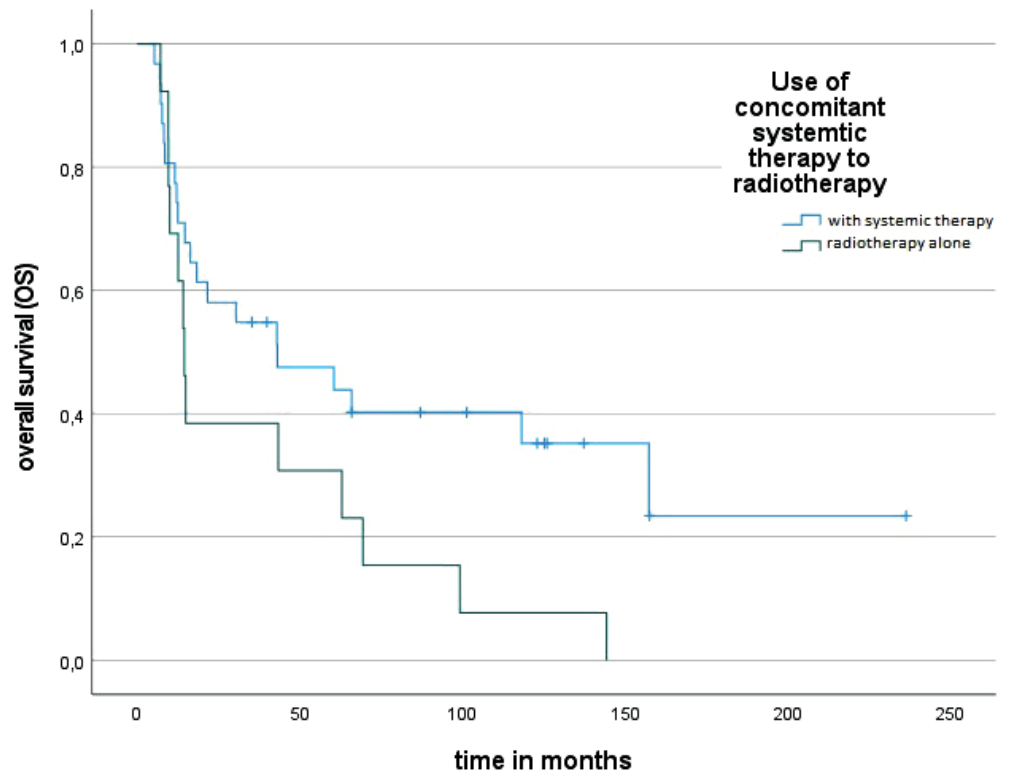

FIGURE 1. The 5-year Kaplan-Meier estimates for overall survival (OS) with systemic treatment (blue) was $43.9 \%$ vs. $23.1 \%$ with radiotherapy alone (green) ( $p=0.05, H R$ $2.1,1.1-4.2)$.

Committee on Cancer (AJCC) Stage III-IV disease ( $\mathrm{n}=29,59.2 \%)$, while there were 20 patients $(40.8 \%)$ that occurred in patients with early (Stage I-II) disease. The 5- and 10-year Kaplan-Meier estimates for OS, PFS, and LDFS were $37.9 \%, 35.9 \%$, and $44.9 \%$, and $23.0 \%, 28.6 \%$, and $36.0 \%$ respectively. The median time to development of distant metastases was 66 months (range, 3.0-236 months).

The 5-year Kaplan Meier estimates for OS using systemic treatment versus RT alone was $43.9 \%$ vs. $23.1 \%$ ( $p=0.05$, Figure 1, HR 2.1, 1.1-4.2), there was no significant difference for PFS and LDFS.

\section{Results of univariate analysis}

The 5-year Kaplan-Meier estimates for OS (III-IV vs. I-II) was $22.8 \%$ vs. $54.2 \%(\mathrm{p}=0.03$, HR 2.090, 1.1-4.2).

On univariate analysis, treatment with RT alone $(\mathrm{p}=0.005)$, RT doses < 70Gy $(\mathrm{p}=0.05)$ and nodal positive stage $(p=0.036)$ were associated with a greater risk of death (Table 3). For LDFS and PFS only positive nodal stage $(p=0.026$ and 0.027$)$ was associated with a significantly worse outcome.

\section{Results of multivariate analysis}

Multivariate analysis was performed using the following variables: type of treatment, RT concept and nodal tumor stage. RT with doses less than 70Gy ( $p=0.046$, HR 2.1 (1.0-4.5) was associated with worse overall survival. Table 3 summarizes univariable cox Regression analysis for OS, PFS, LDFS and metastasis free survival (MFS).

TABLE 3. Overview about univariable cox regression analysis for overall survival (OS), progression free survival (PFS), local disease-free survival (LDFS), and metastasis free survival (MFS) in patients with oral squamous cell carcinoma (OSCC) undergoing definitive radiotherapy

\begin{tabular}{|c|c|c|c|c|c|c|c|c|}
\hline \multirow[t]{2}{*}{ Parameter } & \multicolumn{2}{|c|}{ OS } & \multicolumn{2}{|c|}{ PFS } & \multicolumn{2}{|c|}{ LDFS } & \multicolumn{2}{|c|}{ MFS } \\
\hline & $\begin{array}{c}\text { HR } \\
(95 \% \mathrm{Cl})\end{array}$ & $p$-value & $\begin{array}{c}\mathrm{HR} \\
(95 \% \mathrm{Cl})\end{array}$ & p-value & $\begin{array}{c}\text { HR } \\
(95 \% \mathrm{Cl})\end{array}$ & p-value & $\begin{array}{c}\mathrm{HR} \\
(95 \% \mathrm{Cl})\end{array}$ & $p$-value \\
\hline Age (< 60 years) & $1.2(0.6-2.2)$ & 0.637 & $0.9(0.4-1.7)$ & 0.647 & $0.6(0.3-1.3)$ & 0.224 & $\begin{array}{l}3.4(0.7- \\
16.8)\end{array}$ & 0.120 \\
\hline $\begin{array}{l}\text { Sex } \\
\text { male vs. female }\end{array}$ & $1.2(0.6-2.4)$ & 0.570 & $0.9(0.5-2.0)$ & 0.950 & $1.1(0.5-2.4)$ & 0.881 & $1.3(0.3-5.1)$ & 0.741 \\
\hline $\begin{array}{l}\text { T stage } \\
\text { T1/2 vs. T3/4 }\end{array}$ & $2.1(1.1-4.2)$ & 0.036 & $1.3(1.0-1.8)$ & 0.077 & $1.4(0.9-2.0)$ & 0.072 & $2.1(0.9-4.5)$ & 0.071 \\
\hline $\begin{array}{l}\mathrm{N} \text { stage } \\
\text { NO vs. } \mathrm{N}+\end{array}$ & $2.1(1.1-4.2)$ & 0.036 & $2.4(1.1-5.3)$ & 0.026 & $2.7(1.1-6.3)$ & 0.027 & $2.8(0.8-5.4)$ & 0.071 \\
\hline $\begin{array}{l}\text { RT dose } \\
<70.0 \mathrm{~Gy} \text { vs. } \\
>/=67.0 \mathrm{~Gy}\end{array}$ & $1.9(1.0-3.8)$ & 0.05 & $1.5(0.7-3.1)$ & 0.267 & $1.4(0.6-3.1)$ & 0.393 & $1.7(0.4-7.0)$ & 0.428 \\
\hline Concomitant therapies & $2.1(1.0-4.1)$ & 0.05 & $1.2(0.9-1.5)$ & 0.227 & $1.5(0.7-3.5)$ & 0.294 & $0.4(0.1-3.3)$ & 0.409 \\
\hline $\begin{array}{l}\text { Concomitant therapies } \\
\text { CHT vs. IT }\end{array}$ & $1.2(0.9-1.5)$ & 0.216 & $1.5(0.7-3.3)$ & 0.296 & $1.2(0.6-2.7)$ & 0.586 & $0.7(0.2-2.7)$ & 0.580 \\
\hline $\begin{array}{l}\text { RT technique } \\
\text { IMRT vs. 3D }\end{array}$ & $0.6(0.4-1.2)$ & 0.183 & $0.7(0.3-1.3)$ & 0.258 & $0.7(0.3-1.4)$ & 0.282 & $1.2(0.3-5.0)$ & 0.765 \\
\hline Risk factor history & $1.1(0.8-1.4)$ & 0.536 & $0.9(0.7-1.3)$ & 0.690 & $0.9(0.6-1.1)$ & 0.328 & $1.5(0.7-3.0)$ & 0.295 \\
\hline
\end{tabular}

$\mathrm{CHT}=$ chemotherapy; CTV = clinical target volume; Gy = gray; IMRT = intensity modulated radiotherapy, IT = immunotherapy; LDFS = local disease-free survival; RT = radiotherapy, $\mathrm{SIB}=$ simultaneous integrated boost; $3 \mathrm{D}=$ three dimensional-conformal radiotherapy 


\section{Toxicity}

Mucositis was the most common grade $>3$ acute toxicity present in 19 patients $(39.0 \%)$ followed by dysphagia grade 3 in 12 patients $(24.0 \%)$. Other significant acute toxicities grade $1 / 2$ included dermatitis $(56.3 \%)$ and xerostomia $(39.7 \%)$. There were no treatment-related deaths. Late RT-related complications (grade 3) included xerostomia (64.4\%), loss of taste $(60.3 \%)$, trismus $(26.0 \%)$ and osteoradionecrosis $(9.6 \%)$. A total of $27(56.0 \%)$ patients received a percutaneous endoscopic gastrostomy (PEG) tube: $5(19.2 \%)$ prophylactically (reflecting the prior institutional practice of routine PEG placement prior to treatment), 22 acutely during treatment $(80.8 \%)$. Toxicities are summarized in Table 4.

\section{Discussion}

The primary purpose of the present study was to evaluate the outcome and prognostic factors for patients with unresectable OCC who underwent definitive RT. Several studies reported local control rates and 5-year OS for definitive RT in OCC ranging between $27 \%$ to $70 \%{ }^{9,11,13}$ and $37-67 \%{ }^{14}$, which goes in line with our results.

In our study $59.2 \%$ of patients had advancedstage disease III-IV with significant OS in stage I-II. Over the last decades the role of concomitant systemic therapy has become clearer. Pignon et al. reported in MACH-NC about better outcome and locoregional control rates when using concurrent chemotherapy and RT with a better absolute benefit of $4.5 \%$ at 5 years. ${ }^{9,16}$ In our study there were
TABLE 4. Early and late toxicity after radiotherapy

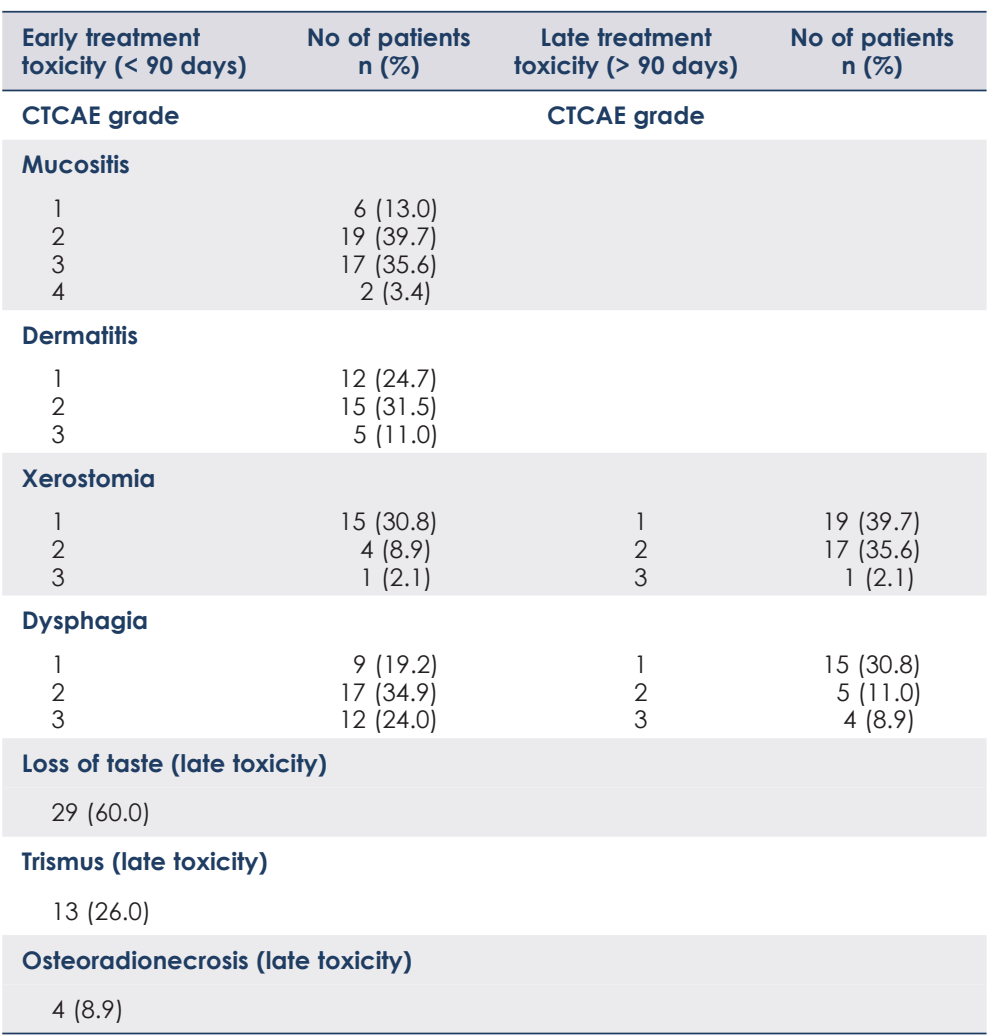

CTCAE $=$ Common Terminology Criteria for Adverse Events

$10.2 \%$ patients treated with RT alone due to either comorbidities, worse performance status or because of denied surgery. Patients who were treated with systemic treatment had a significantly better 5-year OS compared to those without (43.9\% vs.

TABLE 5. Summary of the most important studies for definitive radiotherapy in patients with oral cavity cancer as an overview radiotherapy

\begin{tabular}{|c|c|c|c|c|c|c|c|}
\hline & Study Period & Radiotherapy & No. of patients & CHT/IT & LDFS & PFS & OS \\
\hline Lin ef al. ${ }^{18}$ & 1995-2007 & $42 \%$ IMRT & 115 & $\begin{array}{l}48 \% \\
\text { CHT }\end{array}$ & $27 \%$ (3yr) & $n / a$ & $\begin{array}{l}15 \% \\
(3 y r)\end{array}$ \\
\hline Foster et al. ${ }^{17}$ & 1994-2014 & $54 \%$ IMRT & 140 & $\begin{array}{l}100 \% \\
\mathrm{CHT}\end{array}$ & $\begin{array}{l}79 \% \\
(5 y r)\end{array}$ & $\begin{array}{l}59 \% \\
(5 y r)\end{array}$ & $\begin{array}{l}63 \% \\
(5 y r)\end{array}$ \\
\hline Studer et al. ${ }^{8}$ & 2002-2011 & $100 \%$ IMRT & 54 & $\begin{array}{c}68 \% \\
\text { CHT/IT }\end{array}$ & $n / a$ & $\begin{array}{l}37 \% \\
(4 y r)\end{array}$ & $\begin{array}{l}37 \% \\
(4 y r)\end{array}$ \\
\hline Pederson et al. ${ }^{9}$ & 2001-2004 & $100 \%$ IMRT & 21 & $\begin{array}{c}100 \% \\
\mathrm{CHT}\end{array}$ & $\begin{array}{l}76 \% \\
(5 y r)\end{array}$ & $\begin{array}{l}71 \% \\
(5 y r)\end{array}$ & $\begin{array}{l}76 \% \\
(5 y r)\end{array}$ \\
\hline Hosny et al. ${ }^{19}$ & 2005-2014 & $100 \%$ IMRT & 21 & $\begin{array}{l}35 \% \\
\text { CHT }\end{array}$ & $\begin{array}{l}42 \% \\
(5 y r)\end{array}$ & $\begin{array}{l}78 \% \\
(5 y r)\end{array}$ & $\begin{array}{l}50 \% \\
(5 y r)\end{array}$ \\
\hline Present Study & 2000-2019 & 74\% IMRT & 119 & $\begin{array}{l}86.5 \% \\
\text { CHT/IT }\end{array}$ & $\begin{array}{c}61.9 \% \\
(5 y r)\end{array}$ & $\begin{array}{c}52.1 \% \\
(5 y r)\end{array}$ & $\begin{array}{c}47.2 \% \\
(5 \mathrm{yr})\end{array}$ \\
\hline
\end{tabular}

$\mathrm{CHT}=$ chemotherapy; IMRT = intensity modulated radiotherapy; IT = immunotherapy; LDFS = local disease-free survival; $\mathrm{n} / \mathrm{a}=$ not applicable; OS = overall survival; PFS = progression free survival; $y r=$ years 
$23.1 \%)(\mathrm{p}=0.05$, HR 2.1, 1.1-4.2) but no significant difference for PFS and LDFS.

While other studies found T-stage, age, grading and gender to be prognostic factors for PFS and LC $14-20$, the present study did not find these to have a significant effect in uni- or multivariate analysis. In our collective treatment with RT alone, cumulative total RT doses < 70 Gy and positive nodal stage were associated with a greater risk of death and worse local control. For LDFS and PFS only positive nodal stage was associated with a significant worse outcome.

Cumulative total doses of less than $70 \mathrm{~Gy}$ is standard in patients who underwent postoperative treatment and not suggested as definitive RT treatment concept which goes in line with literature. ${ }^{15}$

Early and late toxicity from definitive RT to the oral cavity of our collective is comparable to data from other published series. $7,9,19,21,22,23$ Most common acute RT-related complications (CTCAE grade $>3$ ) in our study were oral mucositis $(39.0 \%)$ and dysphagia (24.0\%). Other significant acute toxicities grade $1 / 2$ included dermatitis $(56.2 \%)$ and xerostomia (39.7\%). Late RT-related complications included xerostomia (64.4\%), loss of taste $(60.3 \%)$, trismus $(26.0 \%)$, edema (47.3\%). These late complications appear similar in other series. $79,16,19,22$ The rate of osteoradionecrosis in the present study was $9.6 \%$, which falls in line with other studies - ranging from $1 \%$ to $56 \%{ }^{23-28}$ in which both conventional and IMRT were utilized. Reuther et al. reported that a total dose above 60 Gy was a significant parameter for osteoradionecrosis (ORN) ${ }^{29}$ This is similar with our study, all patients with ORN had a cumulative total dose of more than $66 \mathrm{~Gy}$.

The limitations of this study include its retrospective nature, which led to a shortage of necessary data on some single cases. However, we were able to retrieve follow-up data covering a lengthy time period for all patients at a large department with a lot of experience in field of oral tumor diseases.

The power of this study is that we were able to show in a dedicated collective of patients with OCC undergoing definitive RT and an extended follow up of 73 months good control and overall survival rates with moderate toxicity.

\section{References}

1. Scully C, Bagan J. Oral squamous cell carcinoma overview. Oral Oncol 2009; 45: 301-8. doi: 10.1016/j.oraloncology.2009.01.004

2. Warnakulasuriya S. Global epidemiology of oral and oropharyngeal cancer Oral Oncol 2009; 45: 309-16. doi: 10.1016/j.oraloncology.2008.06.002
3. Ferlay J, Colombet M, Soerjomataram I, Mathers C, Parkin DM, Pineros $\mathrm{M}$, et al. Estimating the global cancer incidence and mortality in 2018: GLOBOCAN sources and methods. Int J Cancer 2019; 144: 1941-53. doi: 10.1002/ijc.31937

4. Chaturvedi AK, Anderson WF, Lortet-Tieulent J, Curado MP, Ferlay J, Franceschi $\mathrm{S}$, et al. Worldwide trends in incidence rates for oral cavity and oropharyngeal cancers. J Clin Oncol 2013; 31: 4550-9. doi: 10.1200/ JCO.2013.50.3870

5. Sutton DN, Brown JS, Rogers SN, Vaughan ED, Woolgar JA. The prognostic implications of the surgical margin in the oral squamous cell carcinoma. Int Oral Maxillofac Surg 2003; 32: 30-4. doi: 10.1054/ijom.2002.03135

6. Scher ED, Romesser PB, Chen C, Ho F, Wuu Y, Sherman EJ, et al. Definitive chemoradiation for primary oral cavity carcinoma: a single institution experience. Oral Oncol 2015; 51: 709-15. doi: 10.1016/j.oraloncology.2015.04.007

7. Foster CC, Melotek JM, Brisson RJ, Seiwert TY, Cohen EEW, Stenson KM, et al. Definitive chemoradiation for locally-advanced oral cavity cancer: a 20-year experience. Oral Oncol 2018; 80: 16-22. doi: 10.1016/j.oraloncology.2018.03.008

8. Lyer N, Tan DSW, Tan VKM, Wang W, Hwang J, Tan NC,et al. Randomized trial comparing surgery and adjuvant radiotherapy versus concurrent chemoradiotherapy in patients with advanced, nonmetastatic squamous cell carcinoma of the head and neck: 10-year update and subset analysis. Cancer 2015; 121: 1599-607. doi: 10.1002/cncr.29251

9. Pignon JP, le Maitre A, Maillard E, Bourhis J, Group M-NC. Meta-analysis of chemotherapy in head and neck cancer (MACH-NC): an update on 93 randomised trials and 17,346 patients. Radiother Oncol 2009; 92: 4-14. doi: 10.1016/j.radonc.2009.04.014

10. Stenson KM, Kunnavakkam R, Cohen EE, Portugal LD, Blair E, Haraf DJ, et al. Chemoradiation for patients with advanced oral cavity cancer Laryngoscope 2010; 120: 93-9. doi: 10.1002/lary.20716

11. Studer G, Brown M, Bredell M, Graetz KW, Huber G, Linsenmeier C, et al. Follow up after IMRT in oral cavity cancer: update. Radiat Oncol 2012; 7: 84. doi: $10.1186 / 1748-717 X-7-84$

12. Kessel KA, Bohn C, Engelmann U, Oetzel D, Bougatf N, Bendl R, et al. Fiveyear experience with setup and implementation of an integrated database system for clinical documentation and research. Comput Methods Programs Biomed 2014; 114: 206-17. https://doi.org/10.1016/j.cmpb.2014.02.002

13. Lang K, Akbaba S, Held T, Kargus S, Horn D, Bougatf N, et al. Definitive radiotherapy vs. postoperative radiotherapy for lower gingival carcinomas of the mandible: a single-center report about outcome and toxicity. Strahlenther Onkol 2019; 195: 819-29. doi: 10.1007/s00066-019-01484-z

14. Eisbruch A. Intensity-modulated radiation therapy in the treatment of head and neck cancer. Nat Clin Pract Oncol 2005; 2: 34-9. doi: 10.1038/ ncponc0058

15. Huang SH, O'Sullivan B. Oral cancer: current role of radiotherapy and chemotherapy. Med Oral Patol Oral Cir Bucal 2013; 18: e233-40. doi: 10.4317/medoral.18772

16. Pignon JP, Bourhis J, Domenge C, Designe L. Chemotherapy added to locoregional treatment for head and neck squamous-cell carcinoma: three meta-analyses of updated individual data. MACH-NC Collaborative Group. Meta-analysis of chemotherapy on head and neck cancer. Lancet 2000; 355: 949-55. doi: 10.1016/S0140-6736(00)90011-4

17. Bernier J, Cooper JS, Pajak TF, van Glabbeke M, Bourhis J, Forastiere A, et al. Defining risk levels in locally advanced head and neck cancers: a comparative analysis of concurrent postoperative radiation plus chemotherapy trials of the EORTC (\#22931) and RTOG (\# 9501). Head Neck 2005; 27: 843-50. doi: $10.1002 /$ hed.20279

18. Lin $\mathrm{CY}$, Wang HM, Kang CJ, Lee LY, Huang SF, Fan $\mathrm{KH}$, et al. Primary tumor site as a predictor of treatment outcome for definitive radiotherapy of advanced-stage oral cavity cancers. Int J Radiat Oncol Biol Phys 2010; 78: 1011-9. doi: 10.1016/j.jijobp.2009.09.074

19. Hosni A, Chiu K, Huang SH, Xu W, Huang J, Bayley A, et al. Non-operative management for oral cavity carcinoma: definitive radiation therapy as a potential alternative treatment approach. Radiother Oncol 2020; 154: 70-5. doi: 10.1016/j.radonc.2020.08.013

20. Murthy V, Agarwal JP, Laskar SG, Gupta T, Budrukkar A, Pai P, et al. Analysis of prognostic factors in 1180 patients with oral cavity primary cancer treated with definitive or adjuvant radiotherapy. J Cancer Res Ther 2010; 6: 282-9. doi: 10.4103/0973-1482.73360 
21. Zelefsky MJ, Harrison LB, Fass DE, Armstrong JG, Shah JP, Strong EW. Postoperative radiation therapy for squamous cell carcinomas of the oral cavity and oropharynx: impact of therapy on patients with positive surgical margins. Int J Radiat Oncol Biol Phys 1993; 25: 17-21. doi: 10.1016/03603016(93)90139-m

22. Salama JK, Seiwert TY, Vokes EE. Chemoradiotherapy for locally advanced head and neck cancer. J Clin Oncol 2007; 25: 4118-26. doi: 10.1200/ JCO.2007.12.2697

23. Tobias JS, Monson K, Gupta N, Macdougall H, Glaholm J, Hutchison I, et al. Chemoradiotherapy for locally advanced head and neck cancer: 10-year follow-up of the UK Head and Neck (UKHAN1) trial. Lancet Oncol 2010; 11: 66-74. doi:10.1016/S1470-2045(09)70306-7

24. Pederson AW, Salama JK, Witt ME, Stenson KM, Blair EA, Vokes EE, et al. Concurrent chemotherapy and intensity-modulated radiotherapy for organ preservation of locoregionally advanced oral cavity cancer. Am J Clin Oncol 2011; 34: 356-61. doi: 10.1097/COC.0b013e3181e8420b

25. Gebre-Medhin M, Brun E, Engstrom P, Haugen Cange H, HammarstedtNordenvall L, Reizenstein J, Nyman J, et al. ARTSCAN III: a randomized Phase III study comparing chemoradiotherapy with cisplatin versus cetuximab in patients with locoregionally advanced head and neck squamous cell cancer. J Clin Oncol 2021; 39: 38-47. doi: 10.1200/JCO.20.02072

26. Shah JP, Gil Z. Current concepts in management of oral cancer - surgery. Oral Oncol 2009; 45: 394-401. doi: 10.1016/j.oraloncology.2008.05.017

27. Kerr $\mathrm{P}$, Myers $\mathrm{CL}$, Butler J, Alessa $\mathrm{M}$, Lambert $\mathrm{P}$, Cooke AL. Prospective functional outcomes in sequential population based cohorts of stage III/ IV oropharyngeal carcinoma patients treated with $3 \mathrm{D}$ conformal vs. intensity modulated radiotherapy. J Otolaryngol Head Neck Surg 2015; 44: 17. doi: 10.1186/s40463-015-0068-429.

28. Blanchard P, Baujat B, Holostenco V, Bourredjem A, Baey C, Bourhis J, et al. Meta-analysis of chemotherapy in head and neck cancer (MACH-NC): a comprehensive analysis by tumour site. Radiother Oncol 2011; 100: 33-40. doi: 10.1016/j.radonc.2011.05.036

29. Reuther T, Schuster T, Mende U, Kübler A. Osteoradionecrosis of the jaws as a side effect of radiotherapy of head and neck tumour patients - a report of a thirty year retrospective review. Int J Oral Maxillofac Surg 2003; 32: 28995. doi: 10.1054/ijom.2002.0332 